\title{
Recent advances in the detection of interferon-gamma as a TB biomarker
}

\author{
Kaylin Cleo Januarie ${ }^{1} \cdot$ Onyinyechi V. Uhuo ${ }^{1}$ Emmanuel Iwuoha ${ }^{1} \cdot$ Usisipho Feleni ${ }^{2}$
}

Received: 24 August 2021 / Revised: 26 September 2021 / Accepted: 27 September 2021 / Published online: 19 October 2021

(c) Springer-Verlag GmbH Germany, part of Springer Nature 2021

\begin{abstract}
Tuberculosis (TB) is one of the main infectious diseases worldwide and accounts for many deaths. It is caused by Mycobacterium tuberculosis usually affecting the lungs of patients. Early diagnosis and treatment are essential to control the TB epidemic. Interferon-gamma (IFN- $\gamma$ ) is a cytokine that plays a part in the body's immune response when fighting infection. Current conventional antibody-based TB sensing techniques which are commonly used include enzyme-linked immunosorbent assay (ELISA) and interferon-gamma release assays (IGRAs). However, these methods have major drawbacks, such as being time-consuming, low sensitivity, and inability to distinguish between the different stages of the TB disease. Several electrochemical biosensor systems have been reported for the detection of interferon-gamma with high sensitivity and selectivity. Microfluidic techniques coupled with multiplex analysis in regular format and as lab-on-chip platforms have also been reported for the detection of IFN- $\gamma$. This article is a review of the techniques for detection of interferon-gamma as a TB disease biomarker. The objective is to provide a concise assessment of the available IFN- $\gamma$ detection techniques (including conventional assays, biosensors, microfluidics, and multiplex analysis) and their ability to distinguish the different stages of the TB disease.
\end{abstract}

Keywords Aptasensor $\cdot$ Biosensor $\cdot$ Cytokine $\cdot$ Interferon-gamma $\cdot$ Nanoscience and nanotechnology $\cdot$ Tuberculosis

\section{Introduction}

Tuberculosis (TB) is a lethal infectious disease caused by Mycobacterium tuberculosis, which affects the lungs and the respiratory organs of patients $[1,2]$. It is a contagious airborne disease that is transmitted when infectious patients cough, spit, or sneeze [3]. It is among the deadliest diseases in the world, which caused approximately 1.6 million deaths in 2017, surpassing deaths due to human immunodeficiency

Kaylin Cleo Januarie

3241625@myuwc.ac.za

$\triangle$ Usisipho Feleni

felenu@unisa.ac.za

1 SensorLab (University of the Western Cape Sensor Laboratories), University of the Western Cape, 4th Floor Chemical Sciences Building, Robert Sobukwe Road, Bellville 7535, Cape Town, South Africa

2 Institute for Nanotechnology and Water Sustainability (iNanoWS), College of Science, Engineering and Technology, University of South Africa, Florida Campus, Florida Park, Johannesburg 1710, South Africa virus/acquired immune deficiency syndrome (HIV/AIDS) in the same year [4]. Globally, the number of people infected with $M$. tuberculosis bacteria is estimated to be 1.7 billion, which is about $25 \%$ of the world's population [5]. A person infected with $M$. tuberculosis could develop latent TB infection (LTBI), which is described as the lack of TB symptoms, yet having a $5-10 \%$ chance of developing active TB. This poses a significant problem as LTBI individuals are potential future active TB cases, especially in countries that have high HIV burden. The estimated annual rate of TB infection is 9 million, out of which 1.5 million cases are fatal. Patients that are infected with HIV have a high risk of developing active TB, and HIV-TB co-infection is responsible for $20 \%$ of all TB-related deaths. Early diagnosis of active TB followed by treatment with rifampicin, isoniazid, and ethambutol and the identification and preventative treatment of latent TB infection are the most effective methods of controlling TB epidemic [6-8]. The Mantoux tuberculin skin test (TST) is one of the tests used to diagnose TB infection. The test is an intradermal injection of tuberculin purified protein derivative (PPD) and relies on the delayed hypersensitivity of the person's cell-mediated immune response to the tuberculin 
antigens. After the injection, the skin will produce a localized induration in which the diameter is measured in millimeters of the induration and elucidated using risk cutoffs [9]. The test has poor specificity due to the PPD which encompasses a complex mixture of a variety of mycobacterial antigens that are not specific to $M$. tuberculosis with some even being expressed by the Bacille Calmette-Guerin (BCG) vaccine strains and nontuberculosis mycobacteria $[10,11]$. For this reason, the TST is not an effective diagnostic technique, because of the cross-reactivity with nontuberculosis mycobacteria and the Bacille Calmette-Guerin (BCG) vaccine. In addition, the sensitivity of the TST test in patients that have compromised immune systems is poor. Also, the test only detects TB infection, but it is incapable of distinguishing active TB infection from LTBI $[12,13]$. The polymerase chain reaction (PCR)-based technique, GeneXpert MTB/RIF test offers the real-time detection of the $M$. tuberculosis gene and the mutation of the rpoB gene that causes rifampicin resistance, consequently improving detection rates of Mtb. In this technique, the M. tuberculosis and rpoB gene sequence is amplified using PCR and is detected using a molecular beacon. The detection and processing of results are done nearly automatically within $2 \mathrm{~h}$. The test has a disposable plastic cartridge with the necessary buffers and reagents required for processing $[14,15]$. The disadvantages of this technique are that it is expensive, has a low sensitivity for re-infected patients, only detects pulmonary TB infection, and does not detect latent TB infection. A test that uses host biomarkers is a better diagnostic option, since it gives information on the pathological process and the host immune responses to active TB, pulmonary $\mathrm{TB}$, and latent TB infection [16, 17]. A biomarker is a molecule that can be evaluated and measured to display a pathogenic biological process. They can be employed in the development of diagnostic devices and sensors for the detection of various diseases such as cancer, HIV, SARS-CoV-2, and tuberculosis [18-22]. Biomarkers that are specific to a host or a pathogen can provide valuable prognostic information about a patient, with regard to predicting disease reactivation, cure, and vaccine-induced protection [23]. Interferon-gamma (IFN- $\gamma$ ) is among the host biomarkers of TB infection that have been used in TB diagnostics. It is a cytokine that is part of the interferon family that includes different groups of interferon, notable types I, II, and III. Interferon-gamma is type II and is pleiotropic in nature [24]. Interferon-gamma is produced by T cells, natural killer (NK) cells, and NKT cells, and its receptor is expressed on a variety of cell types. The production of interferon-gamma is administered by the secretion of interleukin-12 (IL-12) and interleukin-18 (IL-18) cytokines. These cytokines aid in linking infection with the production of interferon-gamma in the innate immune response. Interferon-gamma induces pro- and anti-inflammatory responses due to the binding of its receptors that initiates the Janus kinase (JAK)/signal transducer and activator of transcription (STAT) signaling pathway $[25,26]$. It is a cytokine that plays a role in the body's immune response when fighting mycobacterial infection; it does this by activating macrophages that kills the intracellular mycobacteria [27, 28]. For this reason, detection of interferon-gamma is important, and over the years, it has been detected using various techniques from immunoassays to optical and electrochemical-based techniques. This article is a review of the advances in IFN- $\gamma$ based TB diagnostics, including the advantages of biosensor techniques over the conventional techniques. Microfluidics and multiplex-based biosensor methods are also reviewed.

\section{Conventional assay techniques}

\section{Interferon-gamma release assay}

Interferon-gamma release assay (IGRA) is an immunebased blood test for M. tuberculosis infection. The principle of the assay is based upon the individuals' $\mathrm{T}$ cell immune response when they are sensitized to tuberculosisspecific antigens which makes them produce interferongamma when they re-encounter mycobacterial antigens. If a substantial amount of interferon-gamma is produced, it would be presumed to be an indication of tuberculosis infection [29]. In this assay, the amount of interferongamma which is released from CD4 and CD8 lymphocytes after stimulation with the tuberculosis antigens is quantified and detected [30]. The antigens used in the assay are culture filtrate protein 10 (CFP10) and early secretory antigenic target 6 (ESAT6). The specificity of this test is better than that of TST, and not affected by prior BCG vaccination [31]. The drawback of the IGRA test is that it has low sensitivity for active TB, especially in patients that have compromised immune systems. The IGRA test does not distinguish between active TB and latent TB infections, and thus, it is not recommended for the diagnosis of active TB disease [32]. There are three commercially available interferon-gamma release assays that have been developed to detect interferon-gamma in blood samples. It is the QuantiFERON-TB Gold In-Tube (QFT) assay (Cellestis, Australia), the QuantiFERON-TB Gold Plus (QFT-Plus) assay (Qiagen), and the T-SPOT-TB assay (Immunotec, Oxford). All three have been approved by the US Food and Drug Administration (FDA) and recommended for use by the US Centers for Disease Control and Prevention (CDC). The QFT assay is a whole blood assay that uses enzyme-linked immunosorbent assay (ELISA) to measure the amount of interferon-gamma released in response to in vitro stimulation with tuberculosis antigens CFP-10, ESAT6, and TB7.7 in an in-tube format. The results are expressed as IFN- $\gamma$ per millimeter $[9,33]$. A 
new generation of the QFT assay was introduced in 2015 by Qiagen named the QuantiFERON-TB Gold Plus (QFTPlus) assay. This assay includes an additional antigen tube (TB2). TB1 includes antigens CFP-10 and ESAT6 for stimulation of CD4 + T cell response; the antigen TB7.7 that is present in QFT assay has been removed. TB2 includes antigens that were specifically designed to stimulate an immune response from both CD $4+$ and $\mathrm{CD} 8+\mathrm{T}$ cells. This was intended to increase the assays' sensitivity for latent TB infection (LTBI) detection [34, 35]. The T-SPOT-TB assay is an enzyme-linked immunosorbent spot (ELISPOT) assay that uses separated and counted peripheral blood mononuclear cells (PBMCs) that is stimulated with TB-specific antigens ESAT6 and CFP-10; the cells respond to the antigens by producing interferongamma. The results of the reaction are spots of where the interferon-gamma was released. The results are expressed as the number of interferon- $\gamma$-producing $T$ cells (spotforming cells) [9]. Kim et al. [36] hypothesized that combining IFN- $\gamma$ release assay (IGRA) with the tumor necrosis factor-alpha (TNF- $a$ ) release assay could differentiate active TB from latent TB infections. Using the ELISPOT assay on peripheral mononuclear cells, the authors reported a higher sensitivity and specificity (89\% and 93\%) when the IGRA and TNF- $a$ tests were combined, than for IGRA alone [20]. Although their results appeared to be useful for diagnosing active TB, they got indeterminate results from their negative controls and the number of patients involved in the study is not big enough for drawing clinical conclusions. Santos et al. [37] worked on determining and comparing the sensitivity of the IGRA and tuberculin skin test (TST) separately and as a combined approach in active TB patients. The TST induration measurements was understood by making use of two cutoff points: $\geq 5 \mathrm{~mm}$ (TST-5 mm) and $\geq 10 \mathrm{~mm}$ (TST-10 mm). They achieved a higher sensitivity when the two tests were used as a combined approach ( $>90 \%)$. Their study had limitations; they could not approximate the specificity of the tests and they used active TB patients to measure the sensitivity of the tests; therefore, they obtained a different response to patients with LTBI. Garcia et al. [38] determined the sensitivity of the QFT-Plus assay in children and adolescents with tuberculosis disease in a setting that has a low TB burden. They did a cross-sectional analysis within the Spanish Pediatric TB research network. They found that the sensitivity of the assay was $82.9 \%$ and the sensitivity in children of $<5$ years was also lower than that in older children $(78.7 \%$ and $86.7 \%)$. In their study, the performance of this assay was not superior to prior generations of QFT assays that achieved a sensitivity of $83 \%$. In the study, the added TB2 tube in the QFT-Gold Plus assay identified a small portion of added cases that did not already indicate a positive response in TB1 tube. The limitations in their study are that their study will not be relevant in high TB burden countries where malnutrition and HIV-infections are common, as opposed to Spain where their study was conducted. They were not able to get the specificity of the QFT-Plus assay and did not include other interferon-gamma release assays in the study to compare with. They concluded their study by stating that the QFT-Plus assay cannot be used as a conjunctive test for TB diagnosis in children and adolescents in low TB burden countries due to the assays' performance not being better than that of previous-generation QuantiFERON-TB Gold in-Tube (QFT-GIT) assay. In a study conducted by Suzukawa et al. [39], they evaluated the levels of cytokine using the QFT-Gold Plus assay in active tuberculosis patients. They hoped to find cytokines that would be useful for diagnosing active TB by using the QFT-Gold Plus and comparing it with the QuantiFERON-TB Gold. From their study, they found that in terms of diagnosing active TB, the level of IP-10 was much higher than those of IFN- $\gamma$ suggesting that it can be used as a possible biomarker substitute to IFN- $\gamma$ in the QFT-Plus assay. The levels of the cytokines (IFN- $\gamma$, IL-1RA, IL-2, IP-10, $\mathrm{MCP}-1$, and MCP-1 $\beta$ ) were distinctively varied between the active TB patients and the healthy controls, showing these cytokines' participation in the pathogenesis of TB. When comparing the QFT-Gold Plus assay with the QFT assay, no significant superiority was seen between the two regarding the measurement of the cytokines in the supernatants, and the levels of cytokines in the new TB2 tube. The limitations in their study were the notable difference in the background of their patients between the study groups, due to how they recruited the healthy patients, and they did not thoroughly determine if their patients had any immunosuppression or comorbidities among them. In another study, Du et al. [40] detected latent tuberculosis infection and potential active tuberculosis incidence among Chinese college students that tested positive for ELISPOT and TST tests. They used the fusion protein (rESAT-6/CFP-10) ELISPOT assay and those that tested positive from the assay were monitored for 3 years to determine the occurrence of active TB. They achieved a positivity rate of $40.7 \%$ from TST-positive students using the ELISPOT assay with only a few students developing active TB despite having a positive test for TST/ELISPOT assay. They were not able to determine the sensitivity and specificity of the ELISPOT assay in their study and their results were not an accurate reflection of latent tuberculosis infection prevalence due to this study being small scale. Furthermore, Sellami et al. [41] performed a study to determine how in accordance the TST and IGRA are with each other in detecting latent tuberculosis infection before undergoing biologic therapy in patients diagnosed with inflammatory disease. They discovered that the two tests 
were in poor agreement with each other with the sensitivity of the tests each being low, although the sensitivity of IGRA was higher. They concluded their study stating that because of the higher specificity, interferon-gamma release assay should be used to diagnose latent tuberculosis infection before biologic therapy in chronic immune inflammatory disease patients.

As discussed above, these conventional techniques for detecting interferon-gamma are sensitive and specific; however, they do not offer real-time detection and they require centralized laboratories that are expensive and need skilled technical staff to operate. These are the main drawbacks of these conventional detection methods. Developing portable, real-time, and sensitive techniques to detect interferongamma at an affordable cost is crucial. Due to the advances in the research area of biosensor, microfluidics, and multiplex techniques, the discussion in the following sections of this review will be suitable to accomplish the above-stated objectives.

\section{Sensor detection techniques}

The non-sensor techniques mentioned above for interferongamma detection need skilled personnel and complicated instrumentation that are only available in laboratories. For this reason, there is a need to design a portable system that is sensitive and rapid and that offers real-time analysis. Over the years, the field of biosensors has advanced immensely and has proven to be useful in various research areas from disease diagnostics to food and agriculture industry. Biosensors are analytical devices that contain a bioreceptor and transducer. The bioreceptor is a biological compound (antibodies, enzymes, cells, nucleic acids, etc.) that attaches to a specific analyte. The transducer is a component that relays the biological response into a measurable signal [42, 43]. Biosensors have shown to have advantageous features over conventional detection techniques, such as having high sensitivity and specificity and being able to detect a variety of complex samples. They are also easy to use, portable, and providing real-time detection, which is a promising diagnostic method [44].

\section{Fluorescent aptasensor}

Biosensors that have aptamers as their biorecognition element are called aptasensors [45]. Aptamers are artificial single-stranded DNA or RNA molecules that change their conformation when binding to a target [46, 47]. They have become an alternative to antibodies over recent years due to their more favorable conditions such as high chemical and thermal stability, and their ease of modification, high specificity and affinity for any target, and good reproducibility
[48, 49]. In fluorescent sensors, the biorecognition element or target molecule is labeled with a fluorescent tag and the fluorescent intensity reveals how strong the interaction between target and biorecognition molecule is [50]. Zhang et al. [51] developed a malachite green (MG)-bonded G quadruplex aptamer fluorescence biosensor to detect interferon-gamma (IFN- $\gamma$ ) with high sensitivity and specificity. Nicking enzyme-assisted signal amplification and molecular beacon (MB) track-mediated DNA walker were used as an integrated approach when developing the biosensor. In Fig. 1, the schematic diagram of the biosensor fabrication is revealed. They achieved a limit of detection of $7.65 \mathrm{fM}$ in buffer with a linear range of $0 \mathrm{fM}-20 \mathrm{pM}$ and a recovery range of 95.29-118.08\% in real sample. They were able to accomplish a high sensitivity and specificity to target. Although they were able to achieve high sensitivity and low detection limit, their method is long and includes a lot of steps. Another fluorescent aptasensor was developed by Taghdisi et al. [52]; they used an oligonucleotide with a hairpin structure that contained biotinylated aptamer and poly thymine sequence. The sensor was also based on single-stranded DNA binding protein, streptavidin-coated silica nanoparticles, and fluorescent copper nanoparticles. When no target was added, the aptamer kept its structure, and with ascorbic acid introduction, the copper ions used the stem of the hairpin structure as a template to form fluorescent copper nanoparticles which gave off a high fluorescence intensity. When the target was added, the aptamer lost its structure and a weak fluorescence intensity was measured because less fluorescent copper nanoparticles was formed due to the loss of the aptamer stem region. They achieved a detection limit of $1 \mathrm{pg} / \mathrm{mL}$, a linear range of $10 \mathrm{pg} / \mathrm{mL}-4 \mathrm{ng} / \mathrm{mL}$, and a recovery range of $92.52-98.32 \%$ in spiked human serum samples. In Dhenadhayalon et al.'s study [53], they developed a fluorescent aptasensor that utilized two-dimensional nanosheets $\mathrm{ReS}_{2}$ and $\mathrm{TiS}_{2}$ as their platform. Fluorescence resonance energy transfer (FRET) was observed in their system, in which the fluorescence was quenched and then recovered because of the interaction of the dye-labeled aptamer with the nanosheets and target. The detection limit of interferongamma obtained by them was $57.6 \mathrm{pM}$ and $82.7 \mathrm{pM}$ with a linear range of 0-400 pM and 0-300 pM for $\mathrm{ReS}_{2}$ and TiS respectively. In Wen et al.'s study [54], they too developed a fluorescent sensor but theirs was based on DNA click polymerization. They designed a new fluorescent sandwich that comprised of aptamer/protein/aptamer which proved to be sensitive, selective, and stable during detection, specifically when the sandwich was immobilized with magnetic $\mathrm{Fe}_{3} \mathrm{O}_{4}$ nanoparticles. The fluorescent sensor detected interferongamma to as low as $0.175 \mathrm{fM}$ and obtained a broad linear range of $0.01 \mathrm{pM}$ to $10 \mathrm{nM}$; however, when detected in fetal bovine serum, they attained a detection limit of $1.63 \mathrm{fM}$. In another study done by the same group, Wen et al. [55] 
Fig. 1 Schematic diagram of the fluorescent aptasensor fabrication for IFN- $\gamma$ detection. Copyright 2018 Elsevier [51]

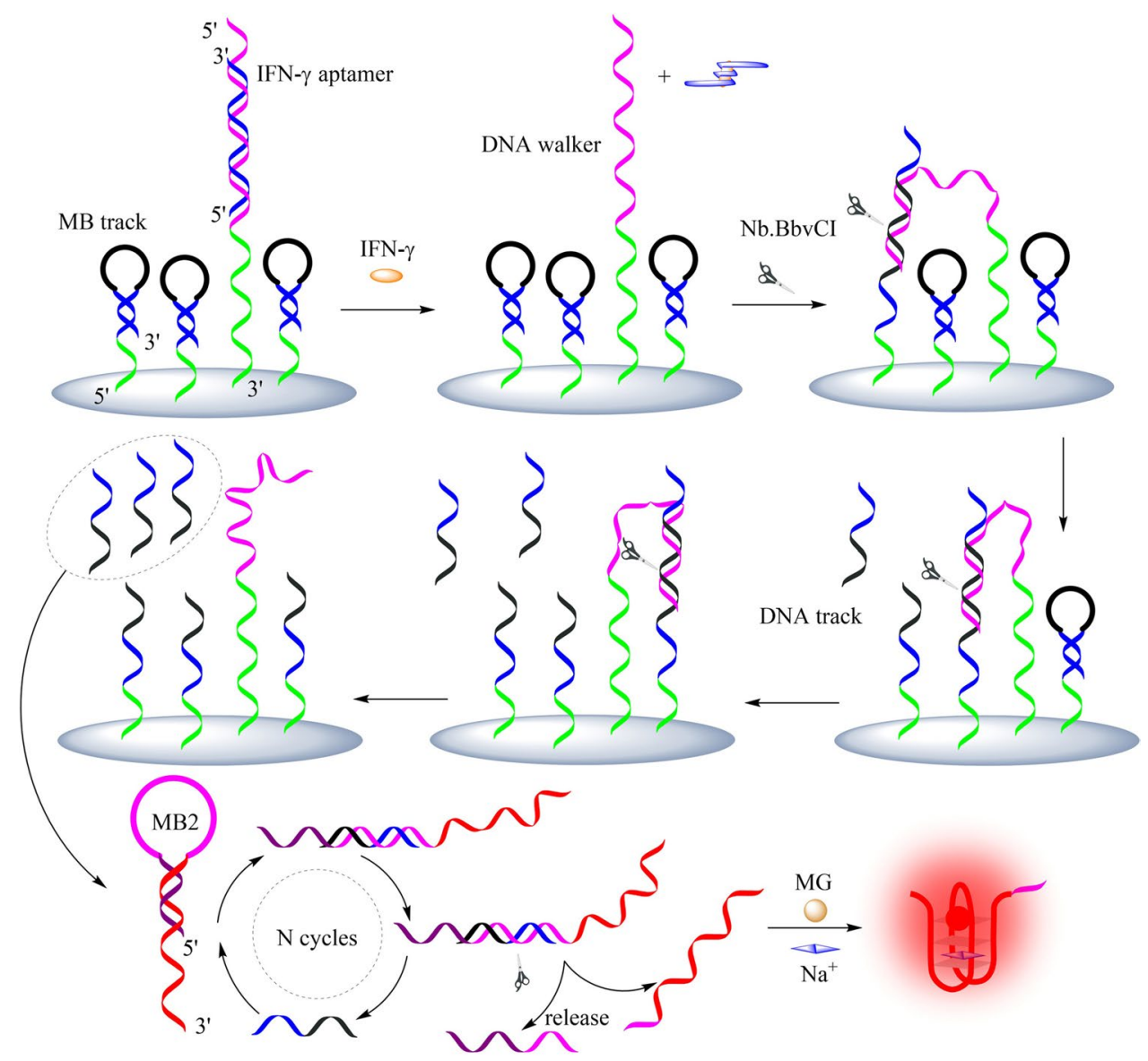

fabricated the sensor utilizing sequential dual atom transfer radical polymerization to amplify their signal. Their first aptamer was immobilized with magnetic $\mathrm{Fe}_{3} \mathrm{O}_{4}$ nanoparticles while the second aptamer was modified with initiators of dual atom transfer radical polymerization. Polymer fluorescein-o-acrylate (FA) grew directly from their nanoparticle surface forming an aptamer/protein/aptamer/polymer super sandwich sensor. The sensor obtained a wide linear range of $0.002 \mathrm{fM}-50 \mathrm{nM}$ with detection limit of $0.178 \mathrm{fM}$ in phosphate buffer and $1.54 \mathrm{fM}$ in human serum.

\section{Electrochemical aptasensor}

Electrochemical sensors are sensing devices that couple a biological recognition element to an electrode transducer; the transducer then converts the biological recognition event into an electrical signal [56]. In a study conducted by $\mathrm{Xu}$ et al. [57], an electrochemical aptasensor was designed that was centered around an aptamer hairpin structure; their hairpin structure was a diblock dual allosteric aptamer. When the target was added, the hairpin structure opened causing hybridization and forming magnesium ion-dependent DNAzymes. The interferon-gamma binding sequence was removed in the presence of magnesium ions causing the allosteric aptamer switching from inactive to active hairpin. Streptavidin-inorganic hybrid nanoflowers with graphene composites (SFG) were prepared and utilized as the platform to the sensor. The binding of the SFG with aptamer conjugated gold nanoparticles caused a high readout signal. A detection limit of $19 \mathrm{fg} / \mathrm{mL}$ and linear range of $0.1 \mathrm{pg} /$ $\mathrm{mL}-500 \mathrm{ng} / \mathrm{mL}$ were attained. Abnous et al. [58] developed an electrochemical aptasensor for the rapid, selective, and sensitive determination of interferon-gamma. The aptasensor was focused on a triple-helix molecular switch (THMS) system, aptamer, and a methylene blue redox probe. When no target was added, the THMS was able to hold its structure on the electrode surface, allowing for the binding with methylene blue which ensued in a high electrochemical signal readout. The addition of target, interferon-gamma, resulted in THMS losing its structure ensuing in the aptamer/IFN- $\gamma$ compound leaving the electrode surface. This caused an insufficient amount of methylene blue to bind to the signal probe on the electrode surface, producing a weak signal readout. They obtained a detection limit of $3 \mathrm{pg} / \mathrm{mL}$ and linear range of $10-1500 \mathrm{pg} / \mathrm{mL}$. They also detected interferon-gamma in spiked serum samples and were able to obtain a recovery range from 91.3 to $102.8 \%$. Although they achieved good results, they had difficulty in designing 
the THMS system for the aptamer to identify its target efficiently. In another study, Li et al. [59] developed a labelfree impedance aptasensor that was based on target-induced exonuclease inhibition. The electron transfer resistance $\left(R_{\mathrm{ct}}\right)$ increased when interferon-gamma was added, because of the double exonuclease reaction taking place. The schematic diagram of the fabrication of the aptasensor is displayed in Fig. 2. The aptasensor attained a detection limit of $0.7 \mathrm{pM}$, a linear range of $1 \mathrm{pM}-50 \mathrm{nM}$, and a recovery range of $91.83-101.9 \%$ in serum samples. Their sensor was found to be low in cost, sensitive, selective, and easy to operate and achieved good reproducibility. In Ding et al.'s study [60], they fabricated an electrochemical aptasensor that consisted of a ternary surface monolayer. The RNA aptamer was immobilized onto a gold interdigited electron array along with 1,6-hexanedithiol (HDT) and 6-mercapto1-hexanolphosphate $(\mathrm{MCH})$. They used a ternary surface monolayer to inhibit nonspecific adsorption of nontarget, improve selectivity, and enable effective hybridization with the target. They detected interferon-gamma in fetal bovine serum and obtained a detection limit of $11.56 \mathrm{pM}$ with a linear range of $22.22 \mathrm{pM}-0.11 \mathrm{nM}$. In another study, Liu et al. [61] developed a gold-centered vertical silicon nanowire aptasensor for the sensitive detection of interferon-gamma. The nanowires were used as working electrodes and were functionalized with methylene blue-labeled aptamer. They compared the nanowire electrode to normal flat electrodes and found the nanowire electrode to be more sensitive with a faster response time. The linear range achieved by the nanowire aptasensor and flat electrode aptasensor was $0.2-100 \mathrm{ng} / \mathrm{mL}$ and $1-280 \mathrm{ng} / \mathrm{mL}$ with a detection limit of $0.14 \mathrm{ng} / \mathrm{mL}$ and $0.8 \mathrm{ng} / \mathrm{mL}$, respectively. Furthermore, Jin et al. [48] fabricated an electrochemical label-free aptasensor that changed conformation from hairpin to linear when binding with the target. They prepared a composite composed of gold nanoparticles, poly(amidoamine) dendrimer, and molybdenum disulfide nanosheets (AuNPs-PAMAM/MoS ${ }_{2}$ ) and used it as a platform for their aptasensor. Methylene blue was used as a redox probe and was absorbed onto the aptamer surface, causing an increase in electrochemical signal. The signal of methylene blue steadily increased as more interferon-gamma was added.

They achieved a linear range of $0.01-1000 \mathrm{pg} / \mathrm{mL}$ with a detection limit of $2 \mathrm{fg} / \mathrm{mL}$ and a recovery range of $95.2-105 \%$ in human serum sample. Lastly, Cao et al. [62] developed a reusable graphene oxide-based aptasensor device to detect interferon-gamma in vivo. The aptamer was labeled with ruthenium ion complex redox probe, $\mathrm{Ru}(\mathrm{NH} 3)_{6}{ }^{3+}$, and it was released when the target was added, causing an increase in current which was measured. They achieved a linear range of $1.3-210 \mathrm{pg} / \mathrm{mL}$ and a detection limit of $1.3 \mathrm{pg} / \mathrm{mL}$. For in vivo interferon-gamma detection, the device was implanted into the tissue of enteritis mice and measured for a long period of time. They achieved promising results for in vivo detection; however, the challenges associated with this method are the background drifting, interferences in complex sample matrix, and the possibility of fouling.

\section{Electrochemical Immunosensor}

When the biorecognition element in a biosensor is an antibody, it is termed an immunosensor. Immunosensors take advantage of the high affinity of antibodies to antigens for determination of specific analytes using an appropriate signal transducer [63]. Sanchez-Tirado et al. [64] designed an electrochemical immunosensor for interferon-gamma detection in saliva. The biosensor was centered on a sandwichtype immunoassay consisting of a capture anti-IFN- $\gamma$ antibody immobilized onto the electrode surface by diazonium salt grafting of p-aminobenzoic acid. Their detector antibody was labeled with biotin and conjugated with streptavidin-horseradish peroxidase. The response was measured amperometrically when adding $\mathrm{H}_{2} \mathrm{O}_{2}$ with hydroquinone being used as a redox couple. They achieved a detection limit of $1.6 \mathrm{pg} / \mathrm{mL}$ and linear range of $2.5-2000 \mathrm{pg} / \mathrm{mL}$.
Fig. 2 Schematic diagram of fabricated electrochemical impedance aptasensor for interferon-gamma determination. Copyright 2019 Elsevier [59]

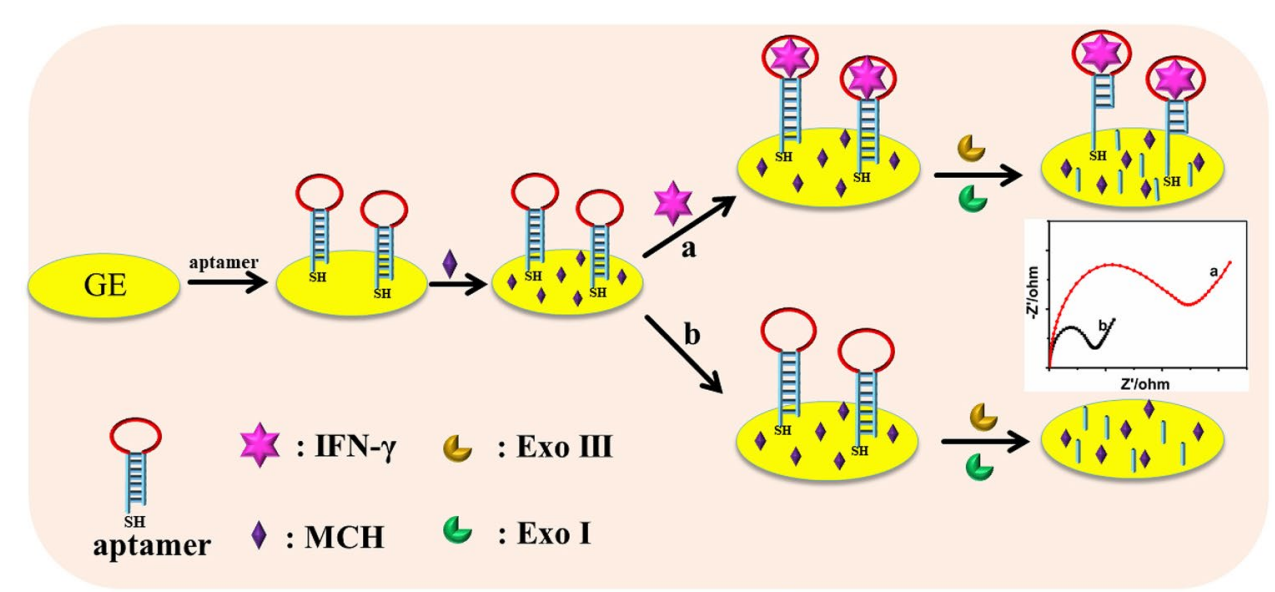


Moreover, Ruecha et al. [65] fabricated a label-free paperbased impedance immunosensor. They modified the paperbased electrode with polyaniline-graphene and immobilized human IFN- $\gamma$ antibody onto it. Electrochemical impedance was used to detect interferon-gamma in human serum with high specificity and with the method proving to be sensitive, simple, rapid, and low in cost. A detection limit of $3.4 \mathrm{pg} /$ $\mathrm{mL}$, linear range of $5-1000 \mathrm{pg} / \mathrm{mL}$, and recovery range of $101-104 \%$ in human serum were realized. Meanwhile, Zhang et al. [66] also developed an electrochemical sandwich-type immunosensor. They designed disposable indium tin oxide electrode and used it to fabricate their immunosensor. On the surface of the electrode, they used a composite comprised of poly(diallyldimethylammonium chloride) (PDDA) and gold nanoparticles to produce an effective biointerface; capture antibody that was labeled with horseradish peroxidase (HRP) and conjugated with gold nanoparticles was used as a signal tag. Hydrogen peroxide was added to aid in HRP's oxidation of hydroquinone, inducing a reduction current. This current was an indication of the amount of immobilized HRP on the electrode surface and was directly correlated to interferon-gamma concentration. Their immunosensor had a detection limit of $0.048 \mathrm{pg} / \mathrm{mL}$ with a wide linear range of $0.1-1 \times 10^{4} \mathrm{pg} / \mathrm{mL}$. Furthermore, Parate et al. [67] designed an immunosensor for determination of cytokines, interferon-gamma and interleukin-10 (IL-10). The immunosensor was based on aerosol-jet printed graphene and they printed the graphene interdigited electrode using nitrocellulose ink on flexible polyimide film. For the IFN- $\gamma$ and IL-10 antibodies to immobilize onto the graphene surface, the electrodes had to undergo $\mathrm{CO}_{2}$ annealing to produce carboxyl groups on the surface. Their immunosensor had a broad linear range: $0.1-5 \mathrm{ng} / \mathrm{mL}$ for IFN- $\gamma$ and $0.1-2 \mathrm{ng} / \mathrm{mL}$ for IL-10. A detection limit of $25 \mathrm{pg} / \mathrm{mL}$ for interferon-gamma and $46 \mathrm{pg} / \mathrm{mL}$ for interleukin-10 was achieved with high selectivity.

\section{Other sensor systems}

There are several other sensor systems that detect interferon-gamma that does not fall under the above categories; some are less common than others. Bao et al. [68] designed an electrochemical biosensor for interferon-gamma detection based on several amplification approaches. Gold nanoclusters-graphene zeolitic imidazolate framework-8 (AuNC-GR@ZIF-8) was used as their platform onto which an improved layered branch hybridization chain reaction took place and consisted of a cascade-like assemblage of four DNA hairpins. Two of the hairpins underwent hybridized chain reaction to form a long DNA double helix while the other two hairpins assisted in the growth of DNA nanostructures. When they added the target, dendritic DNA nanostructures were formed along with several in situ formed hemin/G quadruplex DNAzyme. An amplified signal output was obtained when the DNAzyme caused the catalyzed reduction of $\mathrm{H}_{2} \mathrm{O}_{2}$ and thionine playing the role of electron mediator. The electrochemical signal increased when the concentration of interferon-gamma increased due to the increase of target, enabling the increasing formation of DNA nanostructures that improved the signal. The biosensor obtained a detection limit of $0.6 \mathrm{fM}$ and linear concentration range of $1 \mathrm{fM}-50 \mathrm{pM}$ with a recovery range of 92.35-102.9\% in human serum. In another study, Morales et al. [69] developed a DNA photoacoustic nanosensor for interferon-gamma detection. Photoacoustic sensors are based on the photoacoustic effect, an event that converts optical energy to acoustic waves providing functional and structural information. Their sensor was based on a phthalocyanine dye that increases the photoacoustic signal by $22.5 \%$ when the dyes are stacked using IFN- $\gamma$ receptor mediators. When interferon-gamma binds to the receptors, it caused a conformational change in the DNA that induces dye stacking, which resulted in an increase in photoacoustic signal by $55 \%$ in the presence of $10 \mu \mathrm{M}$ interferon-gamma. Surface plasmon resonance was used to determine the sensors' dynamic range, reversibility, and responsiveness to interferon-gamma. They obtained affinities of $K_{\mathrm{D} 1} 2.8 \mu \mathrm{g} / \mathrm{mL}$ and $K_{\mathrm{D} 2} 5.3 \mu \mathrm{g} / \mathrm{mL}$ with a dynamic range of $0.01-2 \mathrm{ng} / \mathrm{mL}$. Another type of sensor that is used, although rarely, is liquid crystal aptasensor. Liquid crystals are molecules that have fluidity, optical anisotropy, and long-range orientational order that depends on the physical and chemical changes of the adjacent interface [70]. Liquid crystal sensing systems do not require labeling or complicated instrumentation [71]. Kim et al. [72] designed a liquid crystal-based aptasensor for detecting interferon-gamma. The sensor was based on the change in orientation of the liquid crystal when interferon-gamma bound to the surface of the immobilized aptamer. The transformation in the alignment of the liquid crystals was observed by the change in the optical image. When a polarized light microscope was used, a detection limit of $17 \mathrm{pg} / \mathrm{mL}$ was obtained. They used their biosensor to see if it could detect latent TB in blood samples. The blood samples were stimulated with ESAT-6, a TB antigen followed by aptamer incubation on the immobilized surface. Their sensor was successful in detecting latent TB with good sensitivity. Although they achieved promising results, the number of blood samples measured was wanting. Lastly, Pohanka et al. [73] developed a quartz crystal microbalance (QCM) biosensor to detect interferon-gamma. The biosensor was developed for the purpose of being able to compete with the traditional method of detecting IFN- $\gamma$ and for use in on-field application. Monoclonal rat antibodies against 
human interferon-gamma were immobilized onto the gold electrode surface of the quartz crystal microbalance by self-assembled monolayer. Gold nanoparticles were then modified with monoclonal mouse antibody against human interferon-gamma. A sandwich-type assay was formed between the quartz crystal microbalance, IFN- $\gamma$ antibodies, and gold nanoparticles. The biosensor achieved a detection limit of $5.7 \mathrm{pg} / \mathrm{mL}$, and when compared with ELISA, it achieved a better limit of detection; however, when tested on real plasma samples, they achieved similar results. The biosensor had good long-term stability, is simple, cost-effective, and suitable for mass production and does not need any technical laboratory staff to use it. It was concluded that the biosensor can compete with ELISA; however, too little real samples were tested to make this statement. In Table 1, a summary of the various biosensors for interferon-gamma detection is displayed.

\section{Microfluidic-based detection techniques}

In recent years, microfluidic devices have emerged as a possible diagnostic tool to be used in countries with low resources. Microfluidic devices are chip-based sensing techniques that make use of small sample volume to provide real-time, point of care diagnosis of infectious disease. A broad range of clinical samples can be analyzed using microfluidics such as urine, blood, or saliva [74]. The microfluidics can be fabricated on various surfaces such as glass, polydimethylsiloxane (PDMS), silicon, and even paper [75]. They offer the advantage of being low in cost and compact and can be mass produced [76]. Yang et al. [77] fabricated a sensitive microchip electrophoresis chemiluminescence (MCE-CL) assay platform that was focused on cascade signal amplification. They used a double T-type glass microfluidic chip that has a broad Y-type chemiluminescence

Table 1 Various types of biosensors for interferon-gamma detection

\begin{tabular}{|c|c|c|c|c|}
\hline Biosensor devices & Active analytical layer & Linear range $(\mathrm{pg} / \mathrm{mL})$ & $\begin{array}{l}\text { Limit of } \\
\text { detection (pg/ } \\
\mathrm{mL})\end{array}$ & References \\
\hline Fluorescent aptasensor & $\begin{array}{l}\text { DNA walker/IFN- } \gamma \text { aptamer duplex/MB track } \\
\text { and MB2 }\end{array}$ & $0-338$ & 0.129 & {$[51]$} \\
\hline Fluorescent aptasensor & $\begin{array}{l}\text { Oligonucleotide-SNPs-streptavidin-SSB- } \\
\text { CuNPs }\end{array}$ & $10-4000$ & 1 & {$[52]$} \\
\hline Fluorescent aptasensor & Aptamer/target/2DNSs & $\begin{array}{l}\operatorname{ReS}_{2}: 0-6750 \\
\operatorname{TiS}_{2}: 0-5060\end{array}$ & $\begin{array}{l}\operatorname{ReS}_{2}: 972 \\
\operatorname{TiS}_{2}: 1400\end{array}$ & {$[53]$} \\
\hline Fluorescent aptasensor & $\mathrm{Fe}_{3} \mathrm{O}_{4}$-aptamer $1 / \mathrm{IFN}-\gamma /$ aptamer $2 / \mathrm{dsDNA}$ & $0.169-169 \times 10^{5}$ & $2.95 \times 10^{-3}$ & {$[54]$} \\
\hline Fluorescent aptasensor & $\begin{array}{l}\mathrm{Fe}_{3} \mathrm{O}_{4} \text {-aptamer } 1 / \mathrm{IFN}-\gamma / \text { aptamer 2-PBiB- } \\
\text { pBIEM }\end{array}$ & $3.38 \times 10^{-5}-8.44 \times 10^{5}$ & $3 \times 10^{-3}$ & {$[55]$} \\
\hline Electrochemical aptasensor & SFG/GCE/A-DDAH and AuNPs & $0.1-5 \times 10^{5}$ & 0.019 & [57] \\
\hline Electrochemical aptasensor & SPGE/STP/aptamer/MB & $10-1500$ & 3 & {$[58]$} \\
\hline Electrochemical aptasensor & GE/aptamer/IFN- $\gamma /$ Exo I and Exo III & $16.9-8.44 \times 10^{5}$ & 11.8 & [59] \\
\hline Electrochemical aptasensor & $\mathrm{Au}$ IDE/ACP/HDT-MCH & $375-1860$ & 195 & {$[60]$} \\
\hline Electrochemical aptasensor & $\mathrm{Au}-\mathrm{SiNW}$ /MB-aptamer/MCH & $200-1 \times 10^{5}$ & 140 & {$[61]$} \\
\hline Electrochemical aptasensor & Aptamer-AuNPs-PAMAM/MoS $2 / \mathrm{GCE}$ & $0.01-1000$ & 0.002 & {$[48]$} \\
\hline Electrochemical aptasensor & GC-ph-GO-aptamer(Ru) & $1.3-210$ & 1.3 & {$[62]$} \\
\hline Electrochemical immunosensor & $\begin{array}{l}\text { HRP-Strep-biotin-anti-IFN-IFN- } \gamma \text {-anti-IFN- } \\
\text { Phe/SPCE }\end{array}$ & $2.5-2000$ & 1.6 & [64] \\
\hline Paper-based electrochemical immunosensor & $\mathrm{BSA} / \mathrm{hIFN}-\gamma \mathrm{mAb} / \mathrm{PANI}-\mathrm{G}$ electrode & $5-1000$ & 3.5 & {$[65]$} \\
\hline Electrochemical immunosensor & $\begin{array}{l}\text { HRP-Ab2-AuNPs/IFN- } \gamma / \mathrm{BSA} / \mathrm{Ab} 1 / \mathrm{AuNP} / \\
\text { PDDA/ITO }\end{array}$ & $0.1-1 \times 10^{4}$ & 0.048 & {$[66]$} \\
\hline Electrochemical immunosensor & $\begin{array}{l}\text { AJP graphene IDE-anti-IFN- } \gamma \text {-BSA-Tween- } \\
\text { 20-fish gelatin }\end{array}$ & $100-5000$ & 25 & {$[67]$} \\
\hline Electrochemical DNAzyme biosensor & T-DNA/MCH/CP/AuNCs-Gr@ZIF-8/GCE & $0.0169-844$ & 0.01 & {$[68]$} \\
\hline DNA photoacoustic nanosensor & $\begin{array}{l}\text { Streptavidin-coated SPR chip-IFN- } \gamma \text { R2-IFN- } \\
\gamma \mathrm{R} 1-\mathrm{IFN}-\gamma\end{array}$ & $10-2000$ & $\begin{array}{l}K_{\mathrm{D} 1} 2.8 \times 10^{6} \\
K_{\mathrm{D} 2} 5.3 \times 10^{6}\end{array}$ & [69] \\
\hline Liquid crystal aptasensor & $\begin{array}{l}\text { APTES/DMOAP-treated glass-aptamer- } \\
\text { ethanolamine }\end{array}$ & - & 17 & {$[72]$} \\
\hline Quartz crystal microbalance immunosensor & $\begin{array}{l}\text { AuE/cysteamine-glutaraldehyde-anti-IFN- } \gamma \text { - } \\
\text { gelatin }\end{array}$ & - & 5.7 & [73] \\
\hline
\end{tabular}


detection cell. The cascade signal amplification reaction was activated when the aptamer bound to interferon-gamma. DNA labeled with HRP was used as the signal probe for chemiluminescence detection, combined with exonuclease signal amplification strategy which allowed for sensitive and selective detection of interferon-gamma in human plasma. The detection limit achieved was $1.6 \mathrm{fM}$ with a linear range of $8 \times 10^{-15}-1 \times 10^{-8} \mathrm{M}$. In another study, Liu et al. [78] fabricated a microfluidic device that detects interferongamma continuously in blood serum and cell culture. Their microfluidic device included a bottom and top layer with both being PDMS based. It had an inlet, sample channel, sensor loading, and outlet zone. The device was centered on the integrated conformational change of aptamers. Their aptamer hairpin structure was labeled with ferrocene and immobilized onto magnetic nanobeads. They formed their sensing platform by using a magnetic field to confine the aptamer-modified magnetic nanobeads onto the microfluidic chip. When the aptamer bound to interferon-gamma, it lost its structure causing a decrease in electrochemical signal due to the ferrocene molecules moving away from the sensing platform. A diagram of the microfluidic chip and fabrication of the sensing platform is displayed in Fig. 3. The difference in reduction current was directly correlated to interferongamma concentration and a detection limit of $6 \mathrm{pg} / \mathrm{mL}$, linear range of $10-500 \mathrm{pg} / \mathrm{mL}$, and recovery range of $98-102 \%$ in human serum samples were obtained. Furthermore, Evans et al. [79] designed a lab-on printed circuit board sensor platform that contained an in-line assay cells and PMMA microfluidic electrochemical cells. Their system was made to cater for ELISA and was performed under controlled flow. They performed amperometric detection using a multi-channel instrument platform. They obtained a detection limit of
$40 \mathrm{pg} / \mathrm{mL}$ along with a linear range between 15 and $2000 \mathrm{pg} /$ $\mathrm{mL}$ and recovery range of $93-97 \%$ in spiked plasma samples. The performance of the microfluidic biosensor system was comparable to commercial systems in addition to being a microfluidic assay that its whole diagnostic analysis takes an approximate $8 \mathrm{~min}$.

In another study, Baganizi et al. [80] fabricated a PDMSbased microfluidic device combined with an antibody microarray chip to determine $\mathrm{T}$ cell-secreted interferon-gamma and interleukin-2 (IL-2) cytokines. The T cell was captured on the microarray surface after it was injected onto the biochip through the fluidic system and the cytokines secreted during this process were detected when they interacted with their specific antibodies that were grafted near the surrounding area of secreted cells. The secretion of the cytokines was analyzed after a 24-h incubation period using immunofluorescence and continuous surface plasmon resonance imaging. They detected interferon-gamma and interleukin-2 down to nanomolar concentrations, $0.15 \mathrm{nM}$ for IFN- $\gamma$ and $0.1 \mathrm{nM}$ for IL-2 in bulk medium. In Table 2, a summary of the microfluidic techniques for interferon-gamma detection is displayed.

Table 2 Microfluidic devices for interferon-gamma detection

\begin{tabular}{llll}
\hline $\begin{array}{l}\text { Microflu- } \\
\text { idic surface }\end{array}$ & $\begin{array}{l}\text { Linear range } \\
(\mathrm{pg} / \mathrm{mL})\end{array}$ & Limit of detection $(\mathrm{pg} / \mathrm{mL})$ & References \\
\hline Glass & 0.027 & $0.135-1.69 \times 10^{5}$ & {$[74]$} \\
PDMS & $10-500$ & 6 & {$[75]$} \\
PMMA & $15-2000$ & 40 & {$[76]$} \\
PDMS & - & IFN- $\gamma: 2530$ & {$[77]$} \\
& & IL-2: 1690 & \\
\hline
\end{tabular}
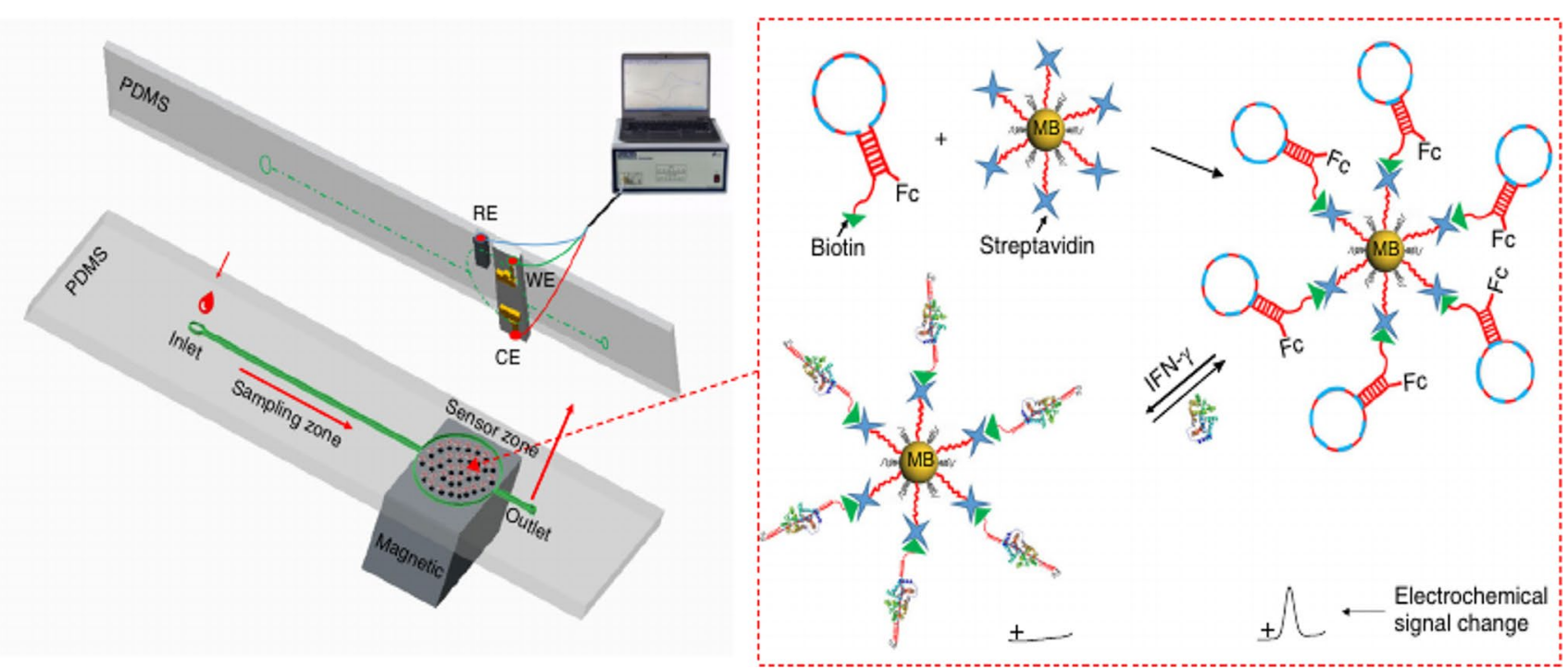

Fig. 3 Schematic diagram of microfluidic chip and fabrication of the sensing platform. Copyright 2019 Creative Commons [78] 


\section{Multiplex detection of TB biomarkers}

Multiplex assay detection is a technique that allows measurement of multiple analytes simultaneously [81]. It has garnered a lot of attention in recent years due to its simplicity, rapidness, requirement of smaller sample volumes, and less consumption of reagents when compared to multiple single target techniques [82]. Wang et al. [83] theorized that using multiplex biomarker assays instead of single cytokine assays to diagnose active TB could enhance the diagnostic performance for TB detection. They analyzed multiple biomarkers with a microbead-based multiplex assay, and among them, five chemokines/cytokines were able to distinguish between active pulmonary TB patients and healthy controls and they were IFN- $\gamma$, interferongamma-inducible protein-10 (IP-10), interferon-gammainduced monokine (MIG), IL-2, and tumor necrosis factor-alpha (TNF-a). They discovered that the multiplex detection of IFN- $\gamma$, IP-10, and IL- 2 achieved a much better diagnostic performance for TB than when detected individually. In another study, Won et al. [84] studied different biomarkers that could distinguish between active and latent TB disease. The biomarkers were measured using a Luminex assay on the supernatants of QuantiFERON tube assay. They found that when measuring a combination of cytokines, they were able to distinguish between different states of TB. The combination of biomarkers that performed the best was IL-5, TNF-a, IL-10, vascular endothelial growth factor (VEGF), and a ratio of IL-2/ IFN- $\gamma$. They accurately predicted $93.3 \%$ of latent TB and $95.5 \%$ of active TB cases. The biomarker that stood out in their study was VEGF because it was able to differentiate between TB states irrespective of stimulation. Yao et al. [85] analyzed multiple chemokines and cytokines in unstimulated and stimulated samples and whether they could be used as potential biomarkers that can be correlated with latent $\mathrm{TB}$ and active $\mathrm{TB}$. The cytokines and chemokines were measured using a multiplex assay based on microbead. In their study, they found that the possible biomarkers that can discern between latent and active TB were IL-8, VEGF, and monocyte chemotactic protein-3 (MCP-3) for stimulated samples and IL-8, IP-10, macrophage inflammatory protein-1 alpha (MIP-1a), and interleukin-2 receptor alpha (IL-2Ra) for unstimulated samples. In Zhou et al.'s [86] study, they fabricated an electrochemiluminescence (ECL) immunosensor to detect IFN- $\gamma$, IL-2, and TNF-a simultaneously. The detection was done on an ITO electrode surface that was spatially spaced to negate interference amongst the ECL probes and employed potential resolved ECL nanoprobes to amplify the electrochemiluminescence signal. The schematic diagram of their immunosensor fabrication process is displayed in Fig. 4. Their immunosensor achieved a detection limit of $1.6 \mathrm{pg} / \mathrm{mL}$ and linear range of $1.6-200 \mathrm{pg} / \mathrm{mL}$ for all three biomarkers. They also detected the three latent TB biomarkers in human serum and obtained a recovery range of 104.2-108.4, 104.8-109.6, and 98.8-105.6\% for IFN- $\gamma$, TNF- $a$, and IL-2, respectively. In another study, Shen et al. [87] developed an electrochemical aptasensor based on aptamer beacons to detect three cytokines (VEGF, IFN- $\gamma$, and TNF-a) simultaneously and in real time. The biotinylated aptamers were labeled with different redox labels for each cytokine and immobilized onto a gold electrode modified with graphene oxide and streptavidin. The conformation of the aptamers changed in the presence of the cytokines, resulting in the redox labels causing a change in electrochemical signal that corresponded to the cytokines' concentration. They achieved a limit of detection of $5 \mathrm{pg} / \mathrm{mL}$ in buffer for each cytokine and a linear range of 5-300 pg/mL for VEGF, 5-300 pg/ $\mathrm{mL}$ for IFN- $\boldsymbol{\gamma}$, and $5-200 \mathrm{pg} / \mathrm{mL}$ for TNF-a.

Chen et al. [88] detected six cytokines (IL-2, IL-4, IL-6, IL-10, TNF- $a$, and IFN- $\gamma$ ) in complex serum matrix. For the analysis, they developed a multiarray localized surface plasmon resonance (LSPR) microfluidic optical biosensor device for parallel detection of the cytokines in micro volume serum sample. They achieved a wide linear range of $10-10,000 \mathrm{pg} / \mathrm{mL}$ for each of the cytokines. The limit of detection for each cytokine biomarker was 11.43, 6.46, $20.56,4.60,11.29$, and $10.97 \mathrm{pg} / \mathrm{mL}$ for TNF- $\mathrm{a}, \mathrm{IFN}-\boldsymbol{\gamma}$, IL-2, IL-4, IL-6, and IL-10, respectively. In Table 3, a summary of the microfluidic techniques for interferon-gamma detection is displayed.

\section{Conclusion}

Tuberculosis is amongst the deadliest diseases in the world and is a massive global health issue. The early detection and diagnosis of this disease are therefore imperative. Over the years, there has been many methods used to detect tuberculosis such as the Mantoux tuberculin skin test and GeneXpert, the PCR-based technique. In this review, we focused on the detection of interferon-gamma, a tuberculosis cytokine biomarker. Interferon-gamma is conventionally detected using the interferon-gamma release assays. They are however labour intensive, do not distinguish between latent and active tuberculosis, and are not sensitive enough especially in immune-compromised patients. With the introduction of the detection of interferon-gamma using biosensing platforms, the sensitivity, specificity, and overall simplicity increased. When compared to conventional techniques, it has exceeded them with regard to accuracy, cost, and time. Despite all the advantages of biosensors, there is still a long way to go to integrate biosensors into real-world clinical 
Fig. 4 Schematic diagram of the fabrication of multiplex immunosensor for determination of latent TB biomarkers. Copyright 2017 American Chemical Society [86]

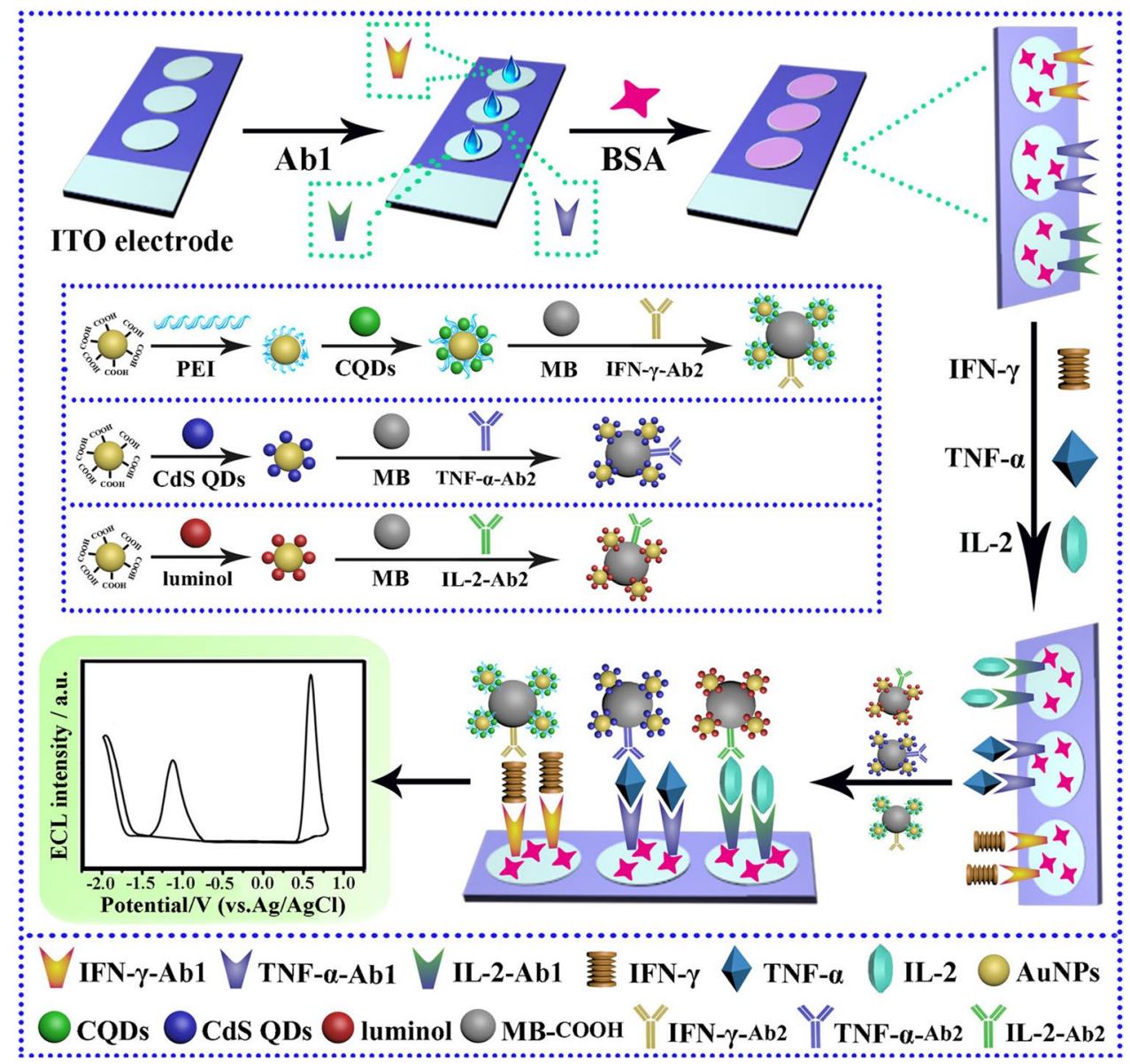

Table 3 Multiplex detection of tuberculosis biomarkers

\begin{tabular}{|c|c|c|c|c|}
\hline Biomarkers measured & Technique used & Detection limit (pg/mL) & Linear range $(\mathrm{pg} / \mathrm{mL})$ & References \\
\hline IFN- $\gamma$, IP-10, MIG, IL-2, and TNF-a & Multiplex assay & $\begin{array}{l}\text { IFN- } \gamma: 1.6 \\
\text { IP-10: } 6 \\
\text { MIG: } 0.9 \\
\text { IL-2: } 16.4 \\
\text { TNF-a: } 3.2\end{array}$ & - & {$[80]$} \\
\hline IL-5, TNF-a, IL-10, VEGF, and IL-2/IFN- $\gamma$ & Multiplex assay & - & - & {$[81]$} \\
\hline IL-8, VEGF, MCP-3, IP-10, MIP-1a, and IL-2Ra & Multiplex assay & - & - & {$[82]$} \\
\hline IFN- $\gamma$, IL-2, and TNF- $a$ & Immunosensor & 1.6 & $1.6-200$ & {$[83]$} \\
\hline VEGF, IFN- $\gamma$, and TNF-a & Aptasensor & 5 & $\begin{array}{l}\text { VEGF: } 5-300 \\
\text { IFN- } \gamma: \text { 5-300 } \\
\text { TNF-a: } 5-200\end{array}$ & [84] \\
\hline IL-2, IL-4, IL-6, IL-10, TNF- $a$, and IFN- $\gamma$ & Microfluidic biosensor & $\begin{array}{l}\text { TNF- } a: 11.43 \\
\text { IFN- } \gamma: 6.46 \\
\text { IL-2: } 20.56 \\
\text { IL-4: } 4.60 \\
\text { IL-6: } 11.29 \\
\text { IL-10: } 10.97\end{array}$ & $10-10,000$ & {$[85]$} \\
\hline
\end{tabular}

applications given that there is such a limited amount used with the glucose sensor being the exception. The introduction of microfluidics and multiplex detection to the sensing systems made diagnosis much easier and can now be used as a lab-on chip platform minimizing the need for laboratory equipment. However, translation of microfluidics into the commercial market has yet to make a big impact due to some challenges that still need to be addressed such as raw 
sample analysis and the cost of mass-producing microfluidics. There is also not adequate research done on multiplexed detection techniques on biosensor platforms and there are no dignified techniques or point of care device that can distinguish the different stages of tuberculosis. If scientists want to control the tuberculosis burden globally, these are the areas that need increased focus along with developing platforms that are inexpensive and reusable and that can be used in developing countries.

\section{Declarations}

Conflict of interest The authors declare no competing interests.

\section{References}

1. Farid S, Meshik X, Choi M, Mukherjee S, Lan Y, Parikh D, Poduri S, Baterdene U, Huang CE, Wang YY, Burke P, Dutta M, Stroscio MA. Detection of Interferon gamma using graphene and aptamer based FET-like electrochemical biosensor. Biosens Bioelectron. 2015;71:294-9. https://doi.org/10.1016/j.bios.2015.04.047.

2. Mishra R, Shukla P, Huang W, Hu N. Gene mutations in Mycobacterium tuberculosis: Multidrug-resistant TB as an emerging global public health crisis. Tuberculosis. 2015;95:1-5. https://doi. org/10.1016/j.tube.2014.08.012.

3. Gupta S, Kakkar V. Recent technological advancements in tuberculosis diagnostics - A review. Biosens Bioelectron. 2018;115:14-29. https://doi.org/10.1016/j.bios.2018.05.017.

4. Daniels B, Kwan A, Pai M, Das J. Lessons on the quality of tuberculosis diagnosis from standardized patients in China, India, Kenya, and South Africa. J Clin Tuberc Other Mycobact Dis. 2019;16: 100109. https://doi.org/10.1016/j.jctube.2019.100109.

5. Garrido-Cardenas JA, de Lamo-Sevilla C, Cabezas-Fernández MT, Manzano-Agugliaro F, Martínez-Lirola M. Global tuberculosis research and its future prospects. Tuberculosis. 2020;121:2-7. https://doi.org/10.1016/j.tube.2020.101917.

6. Horvati K, Bosze S, Gideon HP, Bacsa B, Szabó TG, Goliath R, Rangaka MX, Hudecz F, Wilkinson RJ, Wilkinson KA. Population tailored modification of tuberculosis specific interferongamma release assay. J Infect. 2016;72:179-88. https://doi.org/ 10.1016/j.jinf.2015.10.012.

7. Cao SH, Chen YQ, Sun Y, Liu Y, Zheng SH, Zhang ZG, Li CY. Screening of Serum Biomarkers for Distinguishing between Latent and Active Tuberculosis Using Proteome Microarray. Biomed Environ Sci. 2018;31:515-26. https://doi.org/10.3967/ bes2018.069.

8. Sotgiu G, Centis R, D’Ambrosio L, Battista Migliori G. Tuberculosis treatment and drug regimens. Cold Spring Harb Perspect Med. 2015;1-12. https://doi.org/10.1101/cshperspect.a017822.

9. Pai M, Denkinger CM, Kik SV, Rangaka MX, Zwerling A, Oxlade O, Metcalfe JZ, Cattamanchi A, Dowdy DW, Dheda K, Banaei N. Gamma interferon release assays for detection of Mycobacterium tuberculosis infection. Clin Microbiol Rev. 2014;27:3-20. https:// doi.org/10.1128/CMR.00034-13.

10. Tebruegge M, Dutta B, Donath S, Ritz N, Forbes B, CamachoBadilla K, Clifford V, Zufferey C, Robins-Browne R, Hanekom W, Graham SM, Connell T, Curtis N. Mycobacteria-specific cytokine responses detect tuberculosis infection and distinguish latent from active tuberculosis. Am J Respir Crit Care Med. 2015;192:48599. https://doi.org/10.1164/rccm.201501-0059OC.
11. ECDC. Use of interferon-gamma release assays in support of TB diagnosis. Stockholm; 2011.

12. Frahm M, Goswami ND, Owzar K, Hecker E, Mosher A, Cadogan E, Nahid P, Ferrari G, Stout JE. Discriminating between latent and active tuberculosis with multiple biomarker responses. Tuberculosis. 2011;91:250-6. https://doi.org/10. 1016/j.tube.2011.02.006.

13. Anbarasu D, Ponnu Raja C, Raja A. Multiplex analysis of cytokines/chemokines as biomarkers that differentiate healthy contacts from tuberculosis patients in high endemic settings. Cytokine. 2013;61:747-54. https://doi.org/10.1016/j.cyto.2012. 12.031 .

14. Lawn SD, Mwaba P, Bates M, Piatek A, Alexander H, Marais BJ, Cuevas LE, McHugh TD, Zijenah L, Kapata N, Abubakar I, McNerney R, Hoelscher M, Memish ZA, Migliori GB, Kim P, Maeurer M, Schito M, Zumla A. Advances in tuberculosis diagnostics: The Xpert MTB/RIF assay and future prospects for a point-of-care test. Lancet Infect Dis. 2013;13:349-61. https://doi. org/10.1016/S1473-3099(13)70008-2.

15. Hillemann D, Rüsch-Gerdes S, Boehme C, Richter E. Rapid molecular detection of extrapulmonary tuberculosis by the automated genexpert MTB/RIF system. J Clin Microbiol. 2011;49:1202-5. https://doi.org/10.1128/JCM.02268-10.

16. Yong YK, Tan HY, Saeidi A, Wong WF, Vignesh R, Velu V, Eri R, Larsson M, Shankar EM. Immune Biomarkers for Diagnosis and Treatment Monitoring of Tuberculosis: Current Developments and Future Prospects. Front Microbiol. 2019;10. https:// doi.org/10.3389/fmicb.2019.02789.

17. Manngo PM, Gutschmidt A, Snyders CI, Mutavhatsindi H, Manyelo CM, Makhoba NS, Ahlers P, Hiemstra A, Stanley K, McAnda S, Kidd M, Malherbe ST, Walzl G, Chegou NN. Prospective evaluation of host biomarkers other than interferon gamma in QuantiFERON Plus supernatants as candidates for the diagnosis of tuberculosis in symptomatic individuals. J Infect. 2019;79:228 35. https://doi.org/10.1016/j.jinf.2019.07.007.

18. Ilkhani H, Hughes T, Li J, Zhong CJ, Hepel M. Nanostructured SERS-electrochemical biosensors for testing of anticancer drug interactions with DNA. Biosens Bioelectron. 2016;80:257-64. https://doi.org/10.1016/j.bios.2016.01.068.

19. Stobiecka M, Ratajczak K, Jakiela S. Toward early cancer detection: Focus on biosensing systems and biosensors for an antiapoptotic protein survivin and survivin mRNA. Biosens Bioelectron. 2019;137:58-71. https://doi.org/10.1016/j.bios.2019.04.060.

20. Grel H, Ratajczak K, Jakiela S, Stobiecka M. Gated resonance energy transfer (Gret) controlled by programmed death protein ligand 1. Nanomaterials. 2020;10:1-12. https://doi.org/10.3390/ nano10081592.

21. Zambuzi FA, Cardoso-Silva PM, Espindola MS, Soares LS, Galvão-Lima LJ, Brauer VS, Gomes MS, Amaral LR, Schaller M, Bollela VR, Frantz FG. Identification of promising plasma immune biomarkers to differentiate active pulmonary tuberculosis. Cytokine. 2016;88:99-107. https://doi.org/10.1016/j.cyto. 2016.08.030.

22. Goletti D, Petruccioli E, Joosten SA, Ottenhoff THM. Tuberculosis biomarkers: From diagnosis to protection. Infect Dis Rep. 2016;8:24-32. https://doi.org/10.4081/idr.2016.6568.

23. Markos Abebe AM. Cytokines and Chemokines as Biomarkers of Tuberculosis. Mycobact Dis. 2013;03:2-5. https://doi.org/10. 4172/2161-1068.1000128.

24. Boshtam M, Asgary S, Kouhpayeh S, Shariati L, Khanahmad H. Aptamers Against Pro- and Anti-Inflammatory Cytokines: A Review. Inflammation. 2017;40:340-9. https://doi.org/10.1007/ s10753-016-0477-1.

25. Lin F-C, Young HA. The talented interferon-gamma. Adv Biosci. Biotechnol. 2013;04:6-13. https://doi.org/10.4236/abb.2013. 47A3002. 
26. Schroder K, Hertzog PJ, Ravasi T, Hume DA. Interferon- y : an overview of signals, mechanisms and functions. J Leukoc Biol. 2004;75:163-89. https://doi.org/10.1189/jlb.0603252.Journal.

27. Balcells ME, Ruiz-Tagle C, Tiznado C, García P, Naves R. Diagnostic performance of GM-CSF and IL-2 in response to longterm specific-antigen cell stimulation in patients with active and latent tuberculosis infection. Tuberculosis. 2018;112:110-9. https://doi.org/10.1016/j.tube.2018.08.006.

28. Hussain S, Afzal N, Javaid K, Ullah MI, Ahmad T, Saleem-UzZaman, . Level of interferon gamma in the blood of tuberculosis patients. Iran J Immunol. 2010;7:240-6.

29 Pai M, Riley LW, Colford JM Jr. Interferon- assays in the immunodiagnosis of tuberculosis: a systematic review. Lancet Infect Dis. 2004;4:761-76.

30. Subramaniam SB. Interferon- $\gamma$-release assays (igras) for diagnosis of tuberculosis. Pediatr Infect Dis. 2009;1:33-7. https:// doi.org/10.1016/S2212-8328(09)80008-8.

31. Whitworth HS, Badhan A, Boakye AA, Takwoingi Y, ReesRoberts M, Partlett C, Lambie H, Innes J, Cooke G, Lipman M, Conlon C, Macallan D, Chua F, Post FA, Wiselka M, Woltmann G, Deeks JJ, Kon OM, Lalvani A, Abdoyeku D, Davidson R, Dedicoat M, Kunst H, Loebingher MR, Lynn W, Nathani N, O'Connell R, Pozniak A, Menzies S. Clinical utility of existing and second-generation interferon- $\gamma$ release assays for diagnostic evaluation of tuberculosis: an observational cohort study. Lancet Infect Dis. 2019;19:193-202. https://doi.org/10.1016/ S1473-3099(18)30613-3.

32. Clifford V, Tebruegge M, Zufferey C, Germano S, Forbes B, Cosentino L, Matchett E, McBryde E, Eisen D, Robins-Browne R, Street A, Denholm J, Curtis N. Cytokine biomarkers for the diagnosis of tuberculosis infection and disease in adults in a low prevalence setting. Tuberculosis. 2019;114:91-102. https://doi. org/10.1016/j.tube.2018.08.011.

33. Herrera V, Perry S, Parsonnet J, Banaei N. Clinical application and limitations of interferon- $\gamma$ release assays for the diagnosis of latent tuberculosis infection. Clin Infect Dis. 2011;52:10317. https://doi.org/10.1093/cid/cir068.

34. Pourakbari B, Mamishi S, Benvari S, Mahmoudi S. Comparison of the QuantiFERON-TB Gold Plus and QuantiFERON-TB Gold In-Tube interferon- $\gamma$ release assays: A systematic review and meta-analysis. Adv Med Sci. 2019;64:437-43. https://doi. org/10.1016/j.advms.2019.09.001.

35. Igari H, Akutsu N, Ishikawa S, Aoyama H, Otsuki K, Hasegawa M, Maruyama M, Tsuyuzaki M, Suzuki K, Saigo K. Positivity rate of interferon- $\gamma$ release assays for estimating the prevalence of latent tuberculosis infection in renal transplant recipients in Japan. J Infect Chemother. 2019;25:537-42. https://doi.org/10. 1016/j.jiac.2019.02.018.

36. Kim JY, Park JH, Kim MC, Cha HH, Jeon NY, Park SY, Kim MJ, Chong YP, Lee SO, Choi SH, Kim YS, Woo JH, Kim SH. Combined IFN- $\gamma$ and TNF-a release assay for differentiating active tuberculosis from latent tuberculosis infection. J Infect. 2018;77:314-20. https://doi.org/10.1016/j.jinf.2018.04.011.

37. Santos JA, Duarte R, Nunes C. Host factors associated to false negative and indeterminate results in an interferon- $\gamma$ release assay in patients with active tuberculosis. Pulmonology. 2019. https://doi.org/10.1016/j.pulmoe.2019.11.001.

38. Soler-Garcia A, Gamell A, Santiago B, Monsonís M, Calvo C, Cobo E, et al. Diagnostic Accuracy of QuantiFERON-TB Gold Plus Assays in Children and Adolescents with Tuberculosis Disease. J Pediatr. 2020. https://doi.org/10.1016/j.jpeds.2020.02. 025.

39. Suzukawa M, Takeda K, Akashi S, Asari I, Kawashima M, Ohshima N, Inoue E, Sato R, Shimada M, Suzuki J, Yamane A, Tamura A, Ohta K, Tohma S, Teruya K, Nagai H. Evaluation of cytokine levels using QuantiFERON-TB Gold Plus in patients with active tuberculosis. J Infect. 2020. https://doi.org/10.1016/j. jinf.2020.02.007.

40. Du F, Zhang Z, Gao T, Liu Z, Jia H, Xing A, Du B, Sun Q, Cao $\mathrm{T}$, Zhang Z. Diagnosis of latent tuberculosis by ELISPOT assay and tuberculin skin test. Med Mal Infect. 2016;46:150-3. https:// doi.org/10.1016/j.medmal.2016.02.011.

41. Sellami M, Fazaa A, Cheikh M, Miladi S, Ouenniche K, Ennaifer R, Ben Abdelghani K, Laatar A. Screening for latent tuberculosis infection prior to biologic therapy in patients with chronic immune-mediated inflammatory diseases (IMID): Interferongamma release assay (IGRA) versus tuberculin skin test (TST). Egypt Rheumatol. 2019;41:225-30. https://doi.org/10.1016/j.ejr. 2018.11.003.

42. Kazemi-Darsanaki R, Azizzadeh A, Nourbakhsh M, Raeisi G, AzizollahiAliabadi M. Biosensors: Functions and Applications. J Biol Today's World. 2013;2. https://doi.org/10.15412/j.jbtw. 01020105.

43. Grieshaber D, MacKenzie R, Vörös J, Reimhult E. Electrochemical biosensors - Sensor principles and architectures. Sensors. 2008;8:1400-58. https://doi.org/10.3390/s8031400.

44. García-Basteiro AL, DiNardo A, Saavedra B, Silva DR, Palmero D, Gegia M, Migliori GB, Duarte R, Mambuque E, Centis R, Cuevas LE, Izco S, Theron G. Point of care diagnostics for tuberculosis. Rev Port Pneumol (English Ed). 2018;24:73-85. https:// doi.org/10.1016/j.rppnen.2017.12.002.

45. Song KM, Lee S, Ban C. Aptamers and their biological applications. Sensors. 2012;12:612-31. https://doi.org/10.3390/s1201 00612.

46. Iliuk $\mathrm{AB}, \mathrm{Hu} \mathrm{L}$, Tao WA. Aptamer in bioanalytical applications. Anal Chem. 2011;83:4440-52. https://doi.org/10.1021/ac201 057w.

47. Golichenari B, Nosrati R, Farokhi-Fard A, Abnous K, Vaziri F, Behravan J. Nano-biosensing approaches on tuberculosis: Defy of aptamers. Biosens Bioelectron. 2018;117:319-31. https://doi.org/ 10.1016/j.bios.2018.06.025.

48. Jin H, Gui R, Gao X, Sun Y. An amplified label-free electrochemical aptasensor of $\gamma$-interferon based on target-induced DNA strand transform of hairpin-to-linear conformation enabling simultaneous capture of redox probe and target. Biosens Bioelectron. 2019;145: 111732. https://doi.org/10.1016/j.bios.2019.111732.

49. Song S, Wang L, Li J, Fan C, Zhao J. Aptamer-based biosensors. TrAC - Trends Anal Chem. 2008;27:108-17. https://doi.org/10. 1016/j.trac.2007.12.004.

50. Fan X, White IM, Shopova SI, Zhu H, Suter JD, Sun Y. Sensitive optical biosensors for unlabeled targets: A review. Anal Chim Acta. 2008;620:8-26. https://doi.org/10.1016/j.aca.2008.05.022.

51. Zhang K, Wang K, Huang Y, Zhu X, Xie M, Wang J. Sensitive detection of cytokine in complex biological samples by using MB track mediated DNA walker and nicking enzyme assisted signal amplification method combined biosensor. Talanta. 2018;189:122-8. https://doi.org/10.1016/j.talanta.2018.06.074.

52. Taghdisi SM, Danesh NM, Ramezani M, Yazdian-Robati R, Abnous K. An amplified fluorescent aptasensor based on singlestranded DNA binding protein, copper and silica nanoparticles for sensitive detection of interferon-gamma. Anal Chim Acta. 2017;984:162-7. https://doi.org/10.1016/j.aca.2017.06.032.

53. Dhenadhayalan N, Sriram MI, Lin KC. Aptamer-based fluorogenic sensing of interferon-gamma probed with ReS2 and TiS2 nanosheets. Sensors Actuators B Chem. 2018;258:929-36. https:// doi.org/10.1016/j.snb.2017.11.178.

54. Wen D, Liu Q, Cui Y, Kong J, Yang H, Liu Q. DNA based click polymerization for ultrasensitive IFN- $\Gamma$ fluorescent detection. Sensors Actuators B Chem. 2018;276:279-87. https://doi.org/ 10.1016/j.snb.2018.08.122.

55. Wen D, Liu Q, Li L, Yang H, Kong J. Ultrasensitive aptamer fluorometric detection of $\operatorname{IFN}-\Gamma$ by dual atom transfer 
radical polymerization amplification. Sensors Actuators B Chem. 2019;295:40-8. https://doi.org/10.1016/j.snb.2019.05.036.

56. Wang J. Electrochemical biosensors: Towards point-of-care cancer diagnostics. Biosens Bioelectron. 2006;21:1887-92. https://doi. org/10.1016/j.bios.2005.10.027.

57. Xu L, Lei S, Liu Z, Ouyang G, Zou L, Ye B. A label-free IFN- $\gamma$ aptasensor based on target-triggered allosteric switching of aptamer beacon and streptavidin-inorganic hybrid composites. Anal Chim Acta. 2019;1087:29-35. https://doi.org/10.1016/j. aca.2019.08.034.

58. Abnous K, Danesh NM, Ramezani M, Alibolandi M, Hassanabad KY, Emrani AS, Bahreyni A, Taghdisi SM. A triple-helix molecular switch-based electrochemical aptasensor for interferongamma using a gold electrode and Methylene Blue as a redox probe. Microchim Acta. 2017;184:4151-7. https://doi.org/10. 1007/s00604-017-2457-z.

59. Li H, Song S, Wen M, Bao T, Wu Z, Xiong H, Zhang X, Wen W, Wang S. A novel label-free electrochemical impedance aptasensor for highly sensitive detection of human interferon-gamma based on target-induced exonuclease inhibition. Biosens Bioelectron. 2019;142: 111532. https://doi.org/10.1016/j.bios.2019.111532.

60. Ding S, Mosher C, Lee XY, Das SR, Cargill AA, Tang X, Chen B, Mclamore ES, Gomes C, Hostetter JM, Claussen JC. Rapid and Label-Free Detection of Interferon Gamma via an Electrochemical Aptasensor Comprising a Ternary Surface Monolayer on a Gold Interdigitated Electrode Array. ACS Sensors. 2017;2:210-7. https://doi.org/10.1021/acssensors.6b00581.

61. Liu Y, Rahimian A, Krylyuk S, Vu T, Crulhas B, Stybayeva G, Imanbekova M, Shin D, Davydov A, Revzin A. Nanowire Aptasensors for Electrochemical Detection of Cell-Secreted Cytokines. ACS Sensors. 2017;2:1644-52. https://doi.org/10. 1021/acssensors.7b00486.

62. Cao C, Jin R, Wei H, Yang W, Goldys EM, Hutchinson MR, Liu S, Chen X, Yang G, Liu G. Graphene Oxide Based Recyclable in Vivo Device for Amperometric Monitoring of Interferon- $\gamma$ in Inflammatory Mice. ACS Appl Mater Interfaces. 2018;10:3307887. https://doi.org/10.1021/acsami.8b13518.

63. Shankaran DR, Gobi KV, Miura N. Recent advancements in surface plasmon resonance immunosensors for detection of small molecules of biomedical, food and environmental interest. Sensors Actuators B Chem. 2007;121:158-77. https://doi.org/10.1016/j. snb.2006.09.014.

64. Sánchez-Tirado E, González-Cortés A, Yáñez-Sedeño P, Pingarrón JM. Electrochemical immunosensor for the determination of the cytokine interferon gamma (IFN- $\gamma$ ) in saliva. Talanta. 2020;211: 120761. https://doi.org/10.1016/j.talanta.2020.120761.

65. Ruecha N, Shin K, Chailapakul O, Rodthongkum N. Labelfree paper-based electrochemical impedance immunosensor for human interferon gamma detection. Sensors Actuators B Chem. 2019;279:298-304. https://doi.org/10.1016/j.snb.2018.10.024.

66. Zhang Y, Zhang B, Ye X, Yan Y, Huang L, Jiang Z, Tan S, Cai $X$. Electrochemical immunosensor for interferon- $\gamma$ based on disposable ITO detector and HRP-antibody-conjugated nano gold as signal tag. Mater Sci Eng C. 2016;59:577-84. https://doi.org/10. 1016/j.msec.2015.10.066.

67. Parate K, Rangnekar SV, Jing D, Mendivelso-Perez DL, Ding S, Secor EB, Smith EA, Hostetter JM, Hersam MC, Claussen JC. Aerosol-Jet-Printed Graphene Immunosensor for Label-Free Cytokine Monitoring in Serum. ACS Appl Mater Interfaces. 2020;12:8592-603. https://doi.org/10.1021/acsami.9b22183.

68. Bao T, Wen M, Wen W, Zhang X, Wang S. Ultrasensitive electrochemical biosensor of interferon-gamma based on gold nanoclusters-graphene@zeolitic imidazolate framework-8 and layeredbranched hybridization chain reaction. Sensors Actuators B Chem. 2019;296: 126606. https://doi.org/10.1016/j.snb.2019.05.083.
69. Morales J, Pawle RH, Akkilic N, Luo Y, XavierselVan M, Albokhari R, Calderon IAC, Selfridge S, Minns R, Takiff L, Mallidi S, Clark HA. DNA-Based Photoacoustic Nanosensor for Interferon Gamma Detection. ACS Sensors. 2019;4:1313-22. https:// doi.org/10.1021/acssensors.9b00209.

70. Khoshbin Z, Abnous K, Mohammad S, Verdian A. A novel liquid crystal-based aptasensor for ultra-low detection of ochratoxin a using a $\pi$-shaped DNA structure : Promising for future on-site detection test strips. Biosens Bioelectron. 2021;191: 113457. https://doi.org/10.1016/j.bios.2021.113457.

71. Kim H, An Z, Jang C. Label-free optical detection of thrombin using a liquid crystal-based aptasensor. Microchem J. 2018;141:71-9. https://doi.org/10.1016/j.microc.2018.05.010.

72. Kim HJ, Jang CH. Liquid crystal-based aptasensor for the detection of interferon- $\Gamma$ and its application in the diagnosis of tuberculosis using human blood. Sensors Actuators B Chem. 2019;282:574-9. https://doi.org/10.1016/j.snb.2018.11.104.

73. Pohanka M. Immunoassay of interferon gamma by quartz crystal microbalance biosensor. Talanta. 2020;218: 121167. https://doi. org/10.1016/j.talanta.2020.121167.

74. Su W, Gao X, Jiang L, Qin J. Microfluidic platform towards point-of-care diagnostics in infectious diseases. J Chromatogr A. 2015;1377:13-26. https://doi.org/10.1016/j.chroma.2014.12.041.

75. Zhang Y, Zuo P, Ye BC. A low-cost and simple paper-based microfluidic device for simultaneous multiplex determination of different types of chemical contaminants in food. Biosens Bioelectron. 2015;68:14-9. https://doi.org/10.1016/j.bios.2014.12.042.

76. Mao X, Huang TJ. Microfluidic diagnostics for the developing world. Lab Chip. 2012;12:1412-6. https://doi.org/10.1039/c2lc9 0022j.

77. Yang X, Zhao J, Chen S, Huang Y, Zhaok S. An ultrasensitive microchip electrophoresis chemiluminescence assay platform for detection of trace biomolecules. J Chromatogr A. 2020;1613. https://doi.org/10.1016/j.chroma.2019.460693.

78. Liu G, Cao C, Ni S, Feng S, Wei H. On-chip structure-switching aptamer-modified magnetic nanobeads for the continuous monitoring of interferon-gamma ex vivo. Microsyst Nanoeng. 2019;5:1-11. https://doi.org/10.1038/s41378-019-0074-1.

79. Evans D, Papadimitriou KI, Vasilakis N, Pantelidis P, Kelleher P, Morgan H, Prodromakis T. A novel microfluidic point-of-care biosensor system on printed circuit board for cytokine detection. Sensors (Switzerland). 2018;18:1-14. https://doi.org/10.3390/ s18114011.

80. Baganizi DR, Leroy L, Laplatine L, Fairley SJ, Heidmann S, Menad S, Livache T, Marche PN, Roupioz Y. A Simple microfluidic platform for long-term analysis and continuous dual-imaging detection of T-Cell secreted IFN- $\gamma$ and IL-2 on antibody-based biochip. Biosensors. 2015;5:750-67. https://doi.org/10.3390/bios5 040750.

81. Zhao Y, Cheng Y, Shang L, Wang J, Xie Z, Gu Z. Microfluidic synthesis of barcode particles for multiplex assays. Small. 2015;11:151-74. https://doi.org/10.1002/smll.201401600.

82. Civit L, Fragoso A, Hölters S, Dürst M, Sullivan CKO. Electrochemical genosensor array for the simultaneous detection of multiple high-risk human papillomavirus sequences in clinical samples. Anal Chim Acta. 2012;715:93-8. https://doi.org/10. 1016/j.aca.2011.12.009.

83. Wang X, Jiang J, Cao Z, Yang B, Zhang J, Cheng X. Diagnostic performance of multiplex cytokine and chemokine assay for tuberculosis. Tuberculosis. 2012;92:513-20. https://doi.org/10.1016/j. tube.2012.06.005.

84. Won EJ, Choi JH, Cho YN, Jin HM, Kee HJ, Park YW, Kwon YS, Kee SJ. Biomarkers for discrimination between latent tuberculosis infection and active tuberculosis disease. J Infect. 2017;74:28193. https://doi.org/10.1016/j.jinf.2016.11.010. 
85. Yao X, Liu Y, Liu Y, Liu W, Ye Z, Zheng C, Ge S. Multiplex analysis of plasma cytokines/chemokines showing different immune responses in active TB patients, latent TB infection and healthy participants. Tuberculosis. 2017;107:88-94. https://doi.org/10. 1016/j.tube.2017.07.013.

86. Zhou B, Zhu M, Hao Y, Yang P. Potential-Resolved Electrochemiluminescence for Simultaneous Determination of Triple Latent Tuberculosis Infection Markers. ACS Appl Mater Interfaces. 2017;9:30536-42. https://doi.org/10.1021/acsami.7b10343.

87. Shen Z, Ni S, Yang W, Sun W, Yang G, Liu G. Redox probes tagged electrochemical aptasensing device for simultaneous detection of multiple cytokines in real time. Sensors Actuators B Chem. 2021;336: 129747. https://doi.org/10.1016/j.snb.2021.129747.
88. Chen P, Chung MT, McHugh W, Nidetz R, Li Y, Fu J, Cornell TT, Shanley TP, Kurabayashi K. Multiplex serum cytokine immunoassay using nanoplasmonic biosensor microarrays. ACS Nano. 2015;9:4173-81. https://doi.org/10.1021/acsnano.5b00396.

Publisher's note Springer Nature remains neutral with regard to jurisdictional claims in published maps and institutional affiliations. 